\title{
Cotton Fibers in Acrylic Facial Epithesis - a Thermal Analyze During Heat Exposure
}

\author{
MARIUS PRICOP ${ }^{1 \#, ~ S E R B A N ~ T A L P O S ~}{ }^{1 * \#}$, CRISTIANA PRICOP ${ }^{1 \#,}$ \\ HORATIU URECHESCU ${ }^{1 \#, ~ C A M E L I A ~ S Z U H A N E K ~}{ }^{1 \#, ~ M A R I U S ~ M A T E A S ~}{ }^{2 \#}$ \\ 1 "Victor Babes" University of Medicine and Pharmacy, Faculty of Dentistry, 2 Eftimie Murgu Sq., 300041, Timisoara, \\ Romania \\ ${ }^{2}$ Politehnica University of Timisoara, 1 Mihai Viteazu Blvd., 300222, Timisoara, Romania
}

\begin{abstract}
Heat cured polymethylmethacrylate (PMMA) has been used as denture bases since 1937. PMMA is a vinyl polymer, made by free radical vinyl polymerization from the monomer methyl methacrylate. After the success of using as prosthetic material in the mouth, PMMA began to be used in other areas, for example in facial prosthetics, for facial epitheses. The facial epitheses are exposed permanently to ambiental changes (temperature, air currents, humidity). Secondary, for a better esthetic effect, in facial epitheses PMMA often contain variables quantities of natural fibers (cotton, wool). Our study has analyzed how a PMMA facial epithesis reacts to temperature changes during heat exposure in the summer, especially depending on the amount of fiber it contains, considering that the biological interface between the prosthesis and facial tissues is sensitive to heat.
\end{abstract}

Keywords: cotton, epithesis, thermal, analyze, heat, exposure

\section{Introduction}

Treatment of maxillofacial diseases can result in severe impairment of the patient aesthetic, selfperception and social life. Cosmetically satisfying results associated with high aesthetic and social reintegration are sometimes possible with facial epitheses. Facial epitheses represents a serious alternative to craniofacial reconstructive surgical techniques.

Heat cured polymethylmethacrylate (PMMA) has been used as denture bases since 1937. PMMA is a vinyl polymer, made by free radical vinyl polymerization from the monomer methyl methacrylate [1, 2]. After the success of PMMA as prosthetic material in the mouth, PMMA began to be used in other areas, for example for facial epitheses. Nowadays, PMMA is one of the main materials used for facial epitheses, along with silicones, natural rubbers, elastomers, polyvinylchlorides.

The main qualities of heat cured polymethylmethacrylate are: excellent esthetics, low water solubility, lack of toxicity, reparability, simple processing technique. PMMA are continuously improved in terms of physical, mechanical and esthetical properties, but they may cause some side effects regarding their biocompatibility [2].

For a more esthetic facial epithesis, the technician uses makeup means. The most frequent, makeup means focuses on epithesis color (extrinsic and intrinsic dyes). In the same purpose, the technician can introduce inside acrylate natural fibers (cotton, wool), which imitate the natural appearance of the skin.

The aim of the study was to measure how the temperatures of the acrylic epithesis with natural fibers inside depend on the surrounding environment temperature. In medical practice, it is a major concern not to cause a thermal discomfort in the acrylic-skin (or mucosa) contact area [3]. In this way, we observed the heat transfer, estimating how the patient feels using the epithesis.

\section{Materials and methods}

Our study aimed to understand the thermal behavior of the acrylic facial epithesis with natural fibers insertions, considering that it is important for the patient to have a certain thermal comfort in all year seasons [4]. We designed an experiment able to objectively quantify how the amount of natural fiber

\footnotetext{
*email:talpos@yahoo.com
} \# All authors have contributed equally 
influences the thermal behavior of facial acrylics epithesis. To serve this purpose, six geometrical identical replacement prostheses were made (Figure 1).

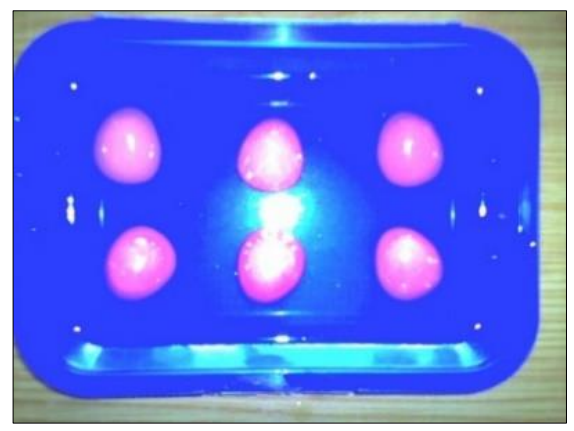

Figure 1. The six geometrical identical replacement prostheses

Each replacement prosthesis was made at a controlled volume of $5 \mathrm{~mL}$ of acryl. In order to emulate a real facial epithesis, the acryl for the replacement prostheses received different amounts of textile fibers. The textile fibers insertions (cotton, round in section, $1 \mathrm{~mm}$ diameter) were cut in small pieces and mixed with the acrylic material. The textile fibers were inserted in the acrylic replacement prostheses as follows: first element- no fiber insertion, the second element- a total length of $3 \mathrm{~mm}$ of fiber insertion, the third element- a total length of $6 \mathrm{~mm}$ of fiber insertion, the fourth element- a total length of $9 \mathrm{~mm}$ of fiber insertion, the fifth element- a total length of $12 \mathrm{~mm}$ of fiber insertion, the sixth element- a total length of $15 \mathrm{~mm}$ of fiber insertion (Figure 2).

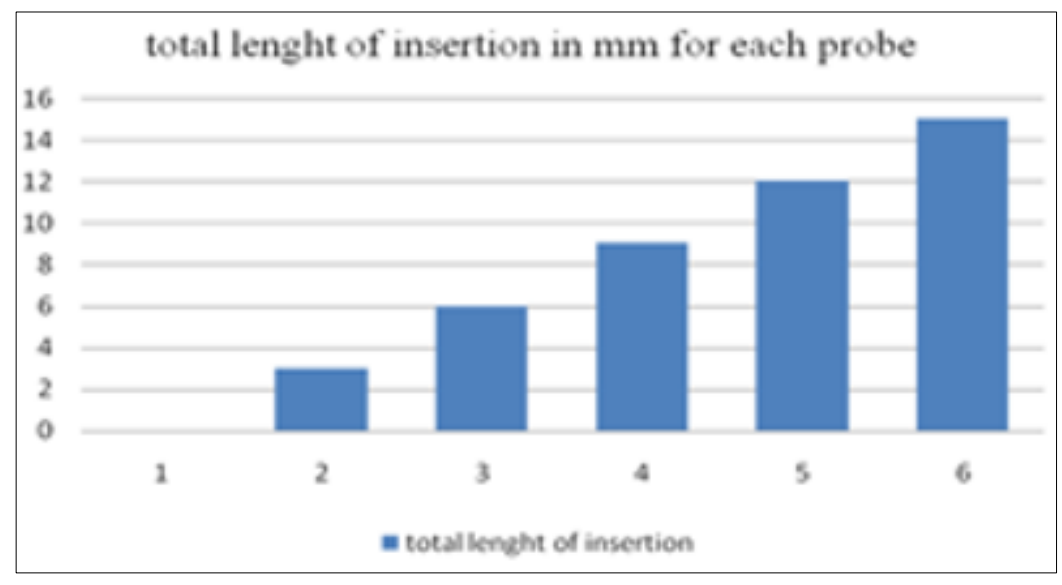

Figure 2. The total length of cotton fiber contained in each replacement prosthesis

After obtaining the six mentioned acrylic replacement prostheses with textile fiber insertions, we watched if the various amount of textile fibers produces changes regarding the thermal behavior of the entire prosthesis. The designed experiment imposed the use of an infrared camera able to detect, measure and display the thermal mapping of the prostheses.

The initial temperature of the prostheses before immersion was $25^{\circ} \mathrm{C}$, representing the ambiental laboratory temperature. The acrylic replacement prostheses were immersed in a saline solution with an artificially raised temperature to $54^{\circ} \mathrm{C}$. We observed that from the saline solution temperature of $54^{\circ} \mathrm{C}$ upwards, visible changes of the replacement prostheses thermal behavior in infrared vision were augmented (Figure 3). The temperature of $54^{\circ} \mathrm{C}$ can be also similar to the direct sun exposure during the summer. 


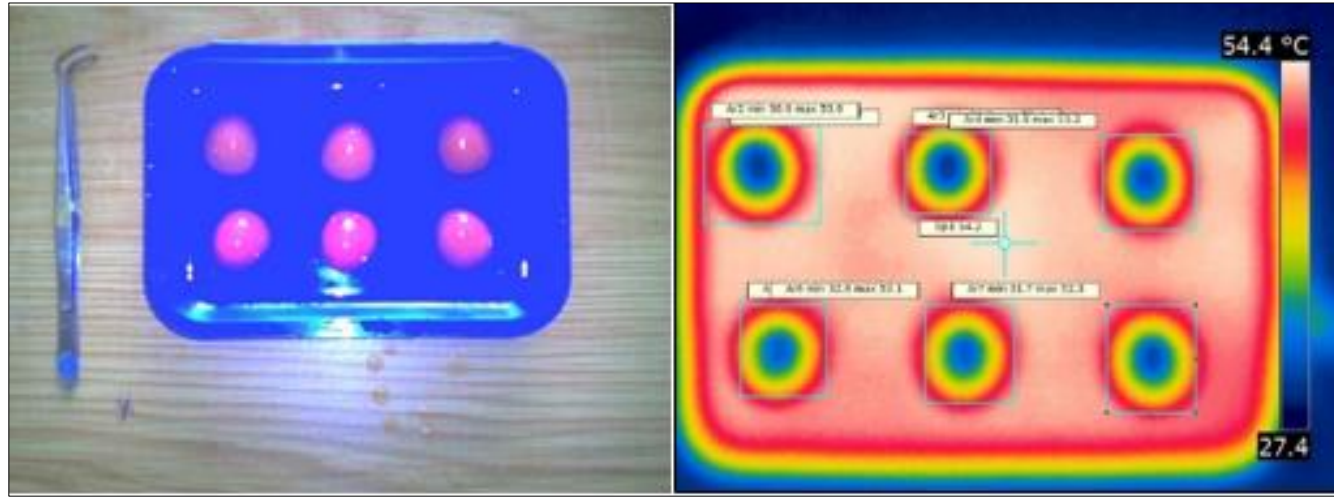

Figure 3. The saline solution tray with the partially immersed 6 replacement prostheses in normal and infrared image

In order to preserve controllable measuring condition during the experiment, the ambient relative humidity was constant (measured using the humidity and ambient temperature meter Mastech MS6503) [5- 7]. This was necessary because in the presence of a variable humidity and air flow convection (air velocity different from zero), the thermal behavior of the prosthesis is changed in an uncontrollable manner.

The acrylic replacement prostheses thermal mapping was performed using a FLIR infrared camera [8-10] after 1, 2, 3, 5 min from immersion. The fourth minute was excluded, based on the fact that it showed no major thermal changes in our experiment.

\section{Results and discussions}

In the field of thermal infrared mapping, the blue area represents the lower temperatures part of the acryl prosthesis ranging from 33.5 to $39.9^{\circ} \mathrm{C}$ and the peripheral layers colored in yellow, orange and red represents the higher temperatures, ranging from 40.2 to $49.4^{\circ} \mathrm{C}[8,9]$. Between these temperatures, the color varies according to the chart at the right of the image (Figure 4).

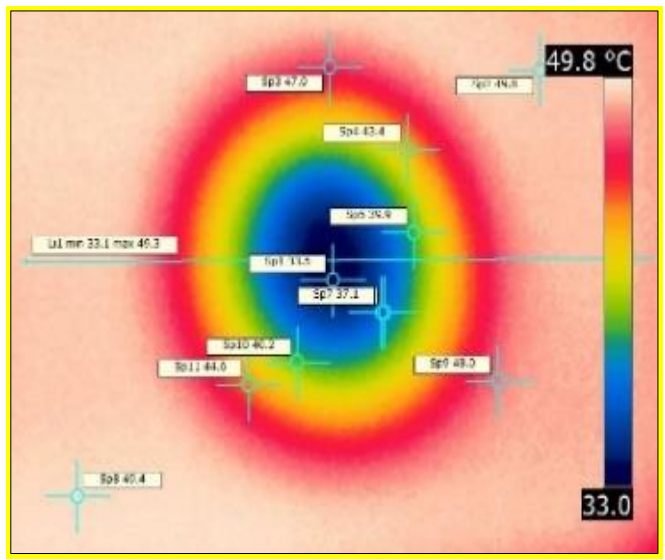

Figure 4. The thermal infrared chromatic map of a replacement prosthesis

The thermal infrared mapping of the six replacement prostheses studied, took a total interval of five minutes measuring at minute $1,2,3$ and 5 .

After 1 min the heat exchange was visible in infrared, as a consequence the saline solution presented a decrease of temperature at $52.2^{\circ} \mathrm{C}$ and the 6 acrylic replacement prostheses displayed a selective increase of the maximal temperatures ranging from 30.9 to $33.1^{\circ} \mathrm{C}$, depending on the amount of the inserted cotton fiber (Figure 5).

After 2 min from the beginning there was a drop in the temperature solution to $42^{\circ} \mathrm{C}$ and a maximal temperature increase for the replacement prostheses ranging from 33.6 to $37.2^{\circ} \mathrm{C}$.

After $3 \mathrm{~min}$ from the beginning there was a drop in temperature for the solution to $36.7^{\circ} \mathrm{C}$ and a 
temperature increase for the replacement prostheses ranging from 33.6 to $35.6^{\circ} \mathrm{C}$.

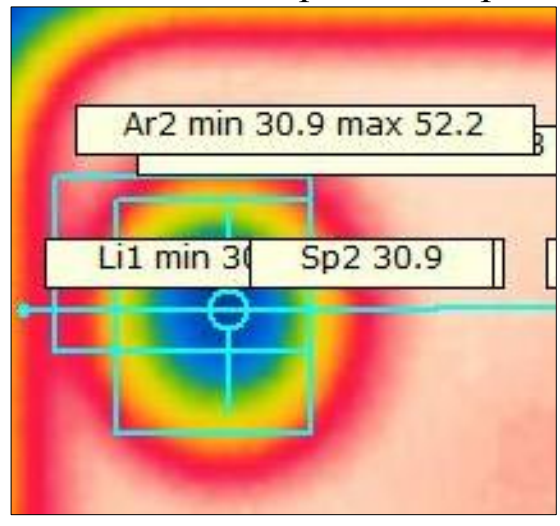

Figure 5. Thermal mapping after $1 \mathrm{~min}$ immersion of the replacement prosthesis

During the thermal mapping procedure, we observed that the temperature modification of the replacement prostheses was influenced by the presence of the textile fiber inserted in the base acrylic material, meaning that more fiber means a better thermal compatibility with the ambient (Figure 6).

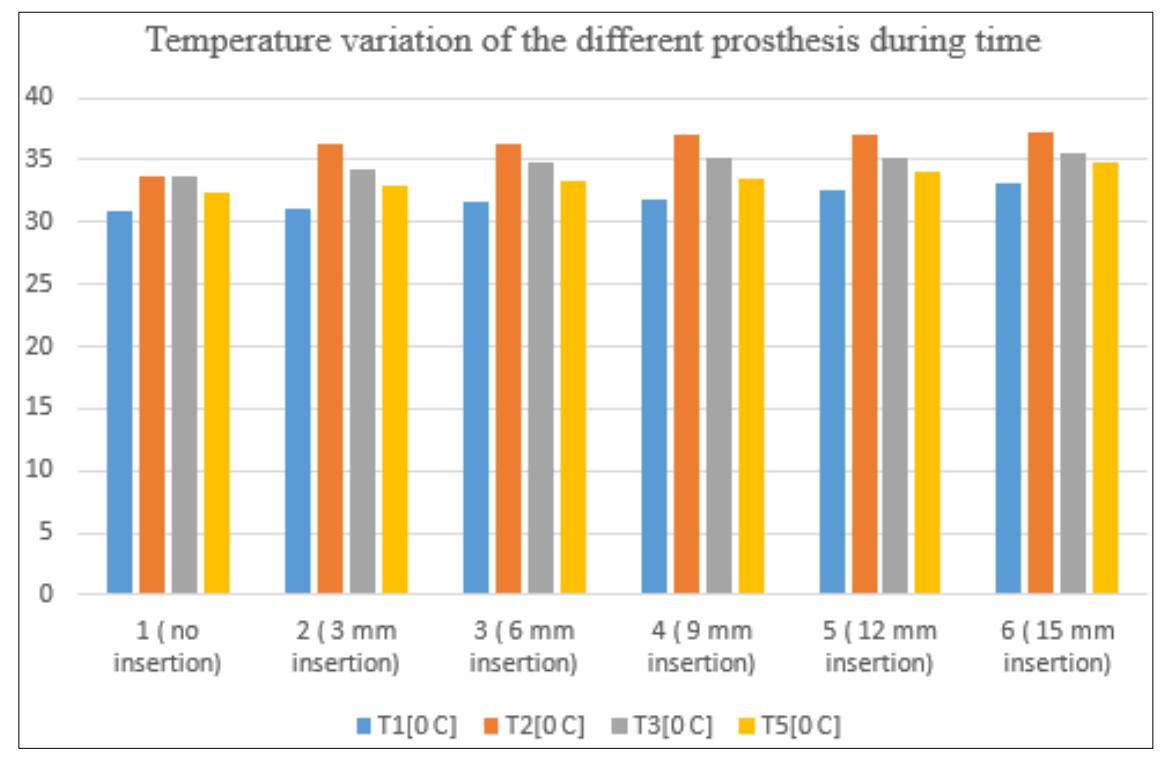

Figure 6. Temperature variation of the prostheses at 1,2,3 and 5 min

Furthermore, the rise of temperature is observed in all central areas of the replacement prostheses, but according to the chromatic scale of temperature, there is an evidence of temperature differences between the samples due to different length of fiber insertions (Table 1).

Table 1- Temperature differences between the samples due to different length of fiber insertions ( $\mathrm{T}$ represents the temperature after 1,2,3 and 5 min of immersion)

\begin{tabular}{|c|c|c|c|c|}
\hline Probe number/ insertion length $[\mathrm{mm}]$ & $\mathrm{T} 1\left[{ }^{0} \mathrm{C}\right]$ & $\mathrm{T} 2\left[{ }^{0} \mathrm{C}\right]$ & $\mathrm{T} 3\left[{ }^{0} \mathrm{C}\right]$ & $\mathrm{T} 5\left[{ }^{0} \mathrm{C}\right]$ \\
\hline 1 (no insertion) & 30.9 & 33.6 & 33.6 & 32.4 \\
\hline 2 (3 mm insertion) & 31 & 36.3 & 34.2 & 33 \\
\hline 3 (6 mm insertion) & 31.7 & 36.3 & 34.8 & 33.4 \\
\hline 4 (9 mm insertion) & 31.8 & 37.1 & 35.2 & 33.5 \\
\hline 5 (12 mm insertion) & 32.6 & 37.1 & 35.2 & 34 \\
\hline 6 (15 mm insertion) & 33.1 & 37.2 & 35.6 & 34.8 \\
\hline
\end{tabular}


We can observe the maximal temperatures differences values between the prostheses during the immersion, showing that the amount of fiber inserted into the prostheses causes differences in thermal behavior (Figure 7).

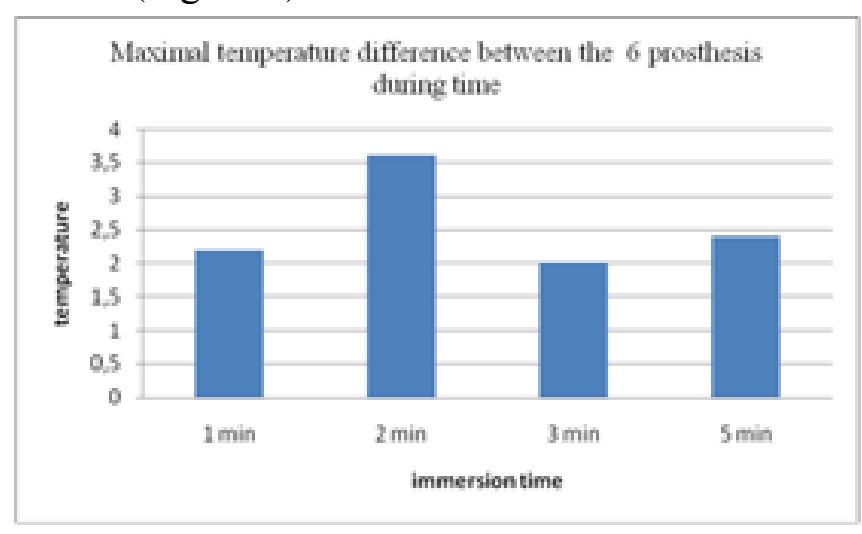

Figure 7. Maximal temperature differences between the six elements at 1 , 2,3 and $5 \mathrm{~min}$

After five minutes of immersion, the acrylic replacement prostheses were hardly observable in infrared, meaning that the heat transfer was accomplished and the temperature differences between the prostheses and the saline solution diminished gradually. At the end of the experiment, the saline solution and the no insertion replacement prosthesis were equal in temperature $\left(32.4^{\circ} \mathrm{C}\right)$ (Figure 8).

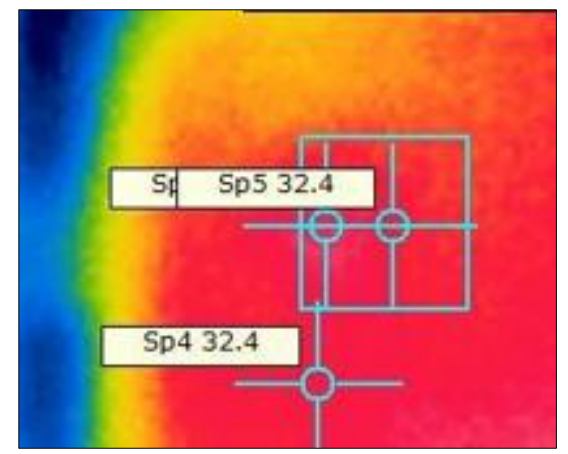

Figure 8. Infrared image showing the same temperature for the no insertion probe and the immersion solution after $5 \mathrm{~min}$ from contact

Based on all infrared thermal mapping images and also from point to point measurement (using the spot function of the software application used for the infrared camera) [8], we concluded that there are temperature differences between the six replacement prostheses, in connection with the amount of textile insertions. There was an obvious rapid absorption of heat, so that the prostheses reached the surrounding simulated temperature. However the heat absorption was different from probe to probe. Variable temperature differences between the replacement prostheses and the surrounding saline solution, ranging from $0^{\circ} \mathrm{C}$ (replacement prosthesis with no insertion) to $2.4^{\circ} \mathrm{C}$ (replacement prosthesis with $15 \mathrm{~mm}$ fiber insertion), after 5 min of immersion, reflected a dependence on the amount of fiber insertion (Figure 9).

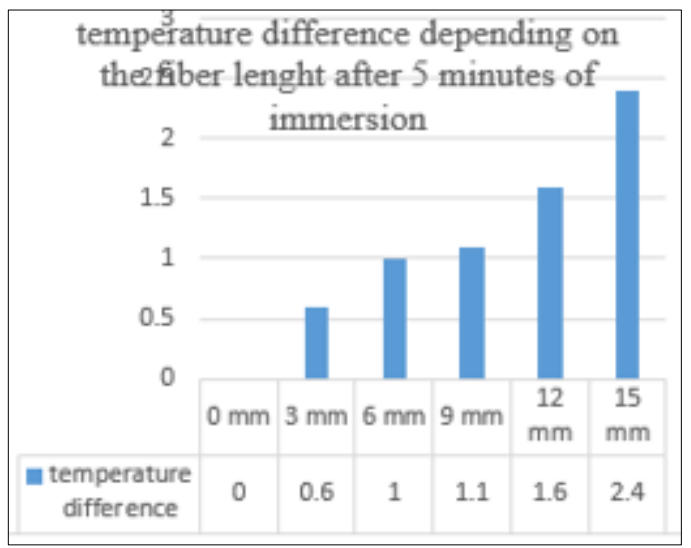

Figure 9. Temperature

differences between the replacement prostheses and the surrounding solution after $5 \mathrm{~min}$ of immersion 
The variable amount of inserted cotton fibers influences the thermal behavior of the prostheses, but not in the manner to change their qualities [11]. As the amount of textile fibers increases in the prosthesis, the time necessary for the heat exchange with the environment increases, but the prosthesis is no less comfortable based on the fact that it is not a provider of a thermal discomfort sensation $[12,13]$.

When the user observes that the prosthesis is warm due to sun exposure, can immerse the prosthesis in a cooler solution at the optimal temperature around $34-35^{\circ} \mathrm{C}$, for no more than $5 \mathrm{~min}$ and reduce the risk of heat propagation [13].

\section{Conclusions}

The cotton fibers inserted in the prostheses influence the thermal behavior but do not change their qualities.

The measurements indicated that all the replacement prostheses displayed a moderate temperature difference, with a minimum of $0^{\circ} \mathrm{C}$ and a maximum of $2.4^{\circ} \mathrm{C}$. We observed a maximal $2.4^{\circ} \mathrm{C}$ difference between the acrylic replacement prostheses temperatures after five minutes of immersion, value recorded on the piece with $15 \mathrm{~mm}$ of inserted fiber $/ 5 \mathrm{~mL}$ acryl.

If the temperature difference in the prosthesis heating need to be limited at $1^{\circ} \mathrm{C}$, then the total length of fiber insertion must resume to about $6 \mathrm{~mm} / 5 \mathrm{~mL}$ acryl.

The temperature analysis in time indicates that the prosthesis with maximal fibers insertion is warmer than the others, meaning that the thermal insulation is stronger and it will react slower to the environment temperatures.

The time needed for the heat exchange with the environment is directly proportional with the amount of textile fibers. The prosthesis is no less comfortable based on the fact that it is not a provider of a thermal discomfort sensation.

A maximal temperature difference of $2.4^{\circ} \mathrm{C}$ after 5 min contact with the experimental solution proves that adding textile fiber to the artificial prosthesis in order to imitate it's natural appearance does not interfere with the functionality and ergonomics.

The risk of heat propagation can be reduced by immersing the prosthesis in a cooler solution at the optimal temperature of $34-35^{\circ} \mathrm{C}$ for no more than $5 \mathrm{~min}$.

\section{References}

1.PRICOP M., URECHESCU H., PRICOP C., ROSU S., PRICOP N., JIVANESCU A. Acrylic Obturator Prosthesis in Maxillary Defects Is an Improvement After Denture Adhesive Application? Mater. Plast., 53(3), 2016, 478-480.

2.URECHESCU H., PRICOP M., BOGDAN L., NES C. S., PRICOP C., RUSU L. C., RIVIS M. Experimental Compression and traction tests on heat - cured PMMA used in maxillary obturator prostheses, Mater. Plast., 53(1), 2016, 76-78.

3.PANAGIOTA N. E., KROKIDA M., POLYZOIS G., GETTLEMAN L., BISHARAT G. I. Effects of outdoor weathering on facial prosthetic elastomers, Volume 99, Issue 1, pp 68-76, January 2011.

4.WEBBER C. Prosthetic sockets: assessment of thermal conductivity. Faculty of The University of Akron, 2014

https://etd.ohiolink.edu/!etd.send_file?accession=akron1404224355\&disposition=inline

5.PERJU D. Măsurări mecanice, Editura Politehnica, Timisoara, 2006, ISBN 978-973-625-397-3

6.HERMAN S. Aparatură medicală. Principiile fizice ale aparaturii medicale moderne, Ed. Teora, 2000.

7.MATEAS M. Aparatură pentru explorări funcţionale, Editura Politehnica, Timisoara, 2002, ISBN 973625-023-7

8.***Flir user manual. http://www.flir.com/cs/emea/en/view/?id=42411

9.COHEN DE Y. B. Biomimetics: Biologically Inspired Technologies by CRC Press ISBN. 2005; 9781420037715 - CAT\# E3163.

10.GOSALIA K, WEILAND J., HUMAYUN M., LAZZI G., Thermal elevation in the human eye and 
head due to the operation of a retinal prosthesis. IEEE Trans Biomed Eng. Aug;51(8):1469-77.

11.CAFIERO-CHIN M., MARQUES C., DANZ H., Ocular Prosthesis: Indications to Management, Canadian Journal of Optometry | 32 Revue Canadienne d 'Optométrie Vol. 77 issue 2, 2014; 24-33.

12.PINE K. R., SLOAN B., JACOBS R. J. The development of measurement tools for prosthetic eye research. doi: 10.1111/j.1444-0938.2012.00754.x.Epub, 2012 Jun 6.

13.WEBBER C. M., KLITTICH M. R., DHINOJWALA A., DAVIS B. L. Thermal conductivities of commercially available prosthetic materials. Journal of Prosthetics and Orthotics, 2014; Volume 26 \& Number 4.

$\overline{\text { Manuscript received: } 18.12 .2020}$ 